\title{
FAKTOR RESIKO PENGETAHUAN DAN EFEK SAMPING TERHADAP KEPATUHAN KONSUMSI TABLET Fe PADA IBU HAMIL DIWILAYAH KERJA PUSKESMAS KOLAKAASI KABUPATEN KOLAKA TAHUN 2019
}

\author{
Winda Dwi Amanda ${ }^{1}$ La Ode Muh. Sety ${ }^{2}$ Lymbran Tina ${ }^{3}$ \\ ${ }_{1,2,3}$ Fakultas Kesehatan Masyarakat Universitas Halu Oleo \\ ${ }^{1}$ windadwiamnd@gmail.com²setydinkes@yahoo.co.idlymbranizzah@gmail.com
}

\begin{abstract}
Abstrak
Secara global, 56 juta wanita hamil 41,8\% terkena anemia, sebagian besar karena kekurangan zat besi. Penanggulangan masalah anemia gizi besi pada saat ini masih terfokus pada pemberian tablet Fe, usaha tersebut akan optimal jika ibu hamil patuh mengkonsumsi tablet Fe sesuai aturan. Tujuan penelitian ini adalah untuk mengetahui faktor risiko kepatuhan mengkonsumsi tablet Fe pada ibu hamil di wilayah kerja puskesmas Kolakaasi Kabupaten Kolaka tahun 2019. Penelitian ini menggunakan desain penelitian case control yakni 35 kasus dan 35 kontrol, yang dilakukan pada bulan Februari 2020. Populasi dalam penelitian ini adalah seluruh ibu hamil trimeseter III yang berada di wilayah kerja Puskesmas Kolakaasi Kabupaten Kolaka, dengan jumlah sampel 70 orang yang diambil menggunakan teknik simple random sampling. Hasil penelitian pada tingkat kepercayaan 95\% menunjukkan yang bukan merupakan faktor risiko kepatuhan konsumsi tablet Fe yakni pengetahuan diperoleh nilai $\mathrm{OR}=1,279$ ( $\mathrm{Cl} 95 \%$ 0,483-3,377), sedangkan efek samping merupakan faktor risiko diperoleh nilai $\mathrm{OR}=5,118$ ( $\mathrm{Cl} 95 \%$ 1,702-15.389) lbu hamil sangat diharapkan berperan aktif menjaga kesehatannya sendiri dengan mengkonsumsi tablet Fe selama kehamilan sesuai dengan anjuran kesehatan.
\end{abstract}

Kata Kunci : Kepatuhan, Pengetahuan, Efek Samping

\begin{abstract}
Globally, 56 million pregnant women $41.8 \%$ are affected by anemia, mostly due to iron deficiency. Tackling the problem of iron nutrition anemia at this time is still focused on giving Fe tablets, the effort will be optimal if pregnant women are obediently consuming Fe tablets according to the rules. The purpose of this study was to determine risk factors for compliance with consuming Fe tablets in pregnant women in the working area of Kolakaasi Community Health Center in Kolaka Regency in 2019. This study used a case control study design of 35 cases and 35 controls, conducted in February 2020. The population in this study is all trimeseter III pregnant women in the work area of Kolakaasi Health Center, Kolaka Regency, with a sample of 70 people taken using simple random sampling technique. The results of the study at the $95 \%$ confidence level showed that it was not a risk factor for compliance with Fe tablet consumption ie knowledge obtained OR value $=1,279(95 \% \mathrm{Cl} 0.483$ 3,377), while side effects were a risk factor obtained $\mathrm{OR}$ value $=5,118(95 \% \mathrm{Cl} 1,702-15,389)$ Pregnant women are expected to play an active role in maintaining their own health by consuming Fe tablets during pregnancy in accordance with health recommendations.
\end{abstract}

Keywords : Compliance, Support, Side Effects 

Vol. 5/No. 2/ April 2020; Issn: 2502-731X

\section{PENDAHULUAN}

Zat besi merupakan suplemen yang mengandung zat besi. Zat besi adalah mineral yang dibutuhkan untuk membentuk sel darah merah ( $\mathrm{Hb})$. Hemoglobin ( $\mathrm{Hb}$ ) yaitu suatu okesigen yang mengahantarkan eritrosit berfungsi penting bagi tubuh. Hemoglobin terdiri dari Fe (zat besi), protoporfirin, dan globin $(1 / 3$ berat $\mathrm{Hb}$ terdiri dari $\mathrm{Fe})^{1}$. WHO mengemukakan secara golobal sekitar 56 juta wanita hamil $41,8 \%$ terkena anemia, sebagian besar karena kekurangan zat besi. Penanggulangan masalah anemia gizi besi pada saat ini masih terfokus pada pemberian tablet $\mathrm{Fe}$, usaha tersebut akan optimal jika ibu hamil patuh mengkonsumsi tablet Fe sesuai aturan².

Kekurangan zat besi adalah kekurangan gizi yang paling umum dan juga paling diabaikan di dunia. Ini juga lazim di negara-negara industri. Dinegara-negara berkembang proporsi ini mencapi $80 \%$ seperti Asia Selatan, membuat ibu hamil rentan terhadap peningkatan risiko kematian dan penurunan kapasitas kerja. Selain itu dampak kekuranngan zat besi pada ibu hamil yaitu dapat mengalami keguguran, melahirkan sebelum waktunta, bayi lahir dengan berat tidak normal, perdarahan sebelum atau pada waktu melahirkan dan pada anemia berat dapat menimvulkan kematian ibu dan bayi. Pada anak dapat mengalami gangguan pertumbuhan, tidak mencapai tinggi yang optimal dan anak menjadi kurang cerdas ${ }^{3}$.

Pemerintah Indonesia telah menrencanakan pemerataan pedistribusian tablet Fe. dimana pemebrian tablet zat besi (Fe) pada ibu hamil dapat dibedakan Fe1 yaitu yang mendapat 30 tablet, Fe2 yaitu yang mendapat 30 tablet dan Fe 3 yang mendapat 30 tablet selama kehamila. Pemberian tablet besi minimal 90 tablet selama kehamilan ${ }^{4}$.

Secara nasional prevalensi cakupan ibu hamil mendapat 90 tablet Fe di Indonesia tahun 2018 adalah (81,16\%), angka ini belum mencapai target renstra tahun 2018 yaitu 95\%. Provinsi dengan cakupan tertinggi pemberian tablet $\mathrm{Fe}$ pada ibu hamil adalah Bengkulu $(99,49)$ dan provinsi dengan cakupan terendah adalah Banten $(32,11 \%)^{5}$. Sedangkan Provinsi Sulawesi Tenggara tahun 2018 cakupan ibu hamil mendapat 90 tablet adalah (74,03\%), angka ini belum mencapai renstra tahun 2018 yaitu 95\% (Profil Kesehatan Provinsi Sultra, 2018) $)^{5}$.

Program berbagai puskesmas dalam pencegahan anemia ibu hamil, dengan memberikan suplemen zat besi sebanyak 90 tablet selama kehamilan. Namun banyak ibu hamil yang menolak atau tidak mematuhi anjuran ini karena berbagai alasan. Kepatuhan minum tablet Fe apabila $\geq 90$ tablet dari tablet besi yang seharusnya diminum.
Kepatuhan ibu hamil minum tablet Fe merupakan faktor penting dalam menjamin peningkatan kadar hemoglobin ibu hamil. Tablet Fe sebagai suplemen yang diberikan pada ibu hamil menurut aturan harus dikonsumsi setiap hari. Namun, karena berbagai faktor misalnya pengetahuan, dukungan keluarga atau suami yang kurang perhatian pada ibu hamil, efek samping tablet yang ditimbulkan dapat memicu seseorang kurang mematuhi konsumsi tablet Fe secara benar, dan sosial budaya yang dianut selama kehamilan secara turun temurun baik dari orang tua/keluarga maupun masyarakat sehingga tujuan dari pemberian tablet Fe tersebut tidak tercapai ${ }^{6}$.

Dari data dinas kesehatan Kabupaten Kolaka tahun 2018, menunjukkan prevalensi ibu hamil mendapat tablet Fe adalah (70,9\%). Sedangkan untuk pemberian tablet Fe berdasarkan puskesmas tahun 2018 di kabupaten Kolaka, puskesmas Kolakaasi yang memiliki cakupan terendah pemberian tablet Fe pada ibu hamil yakni (39\%). Jumlah ibu hamil di puskesmas Kolakaasi tahun 2019 yaitu 339 ibu hamil, dan yang mendapat Fe3 yaitu 306 ibu hamil.

Berdasarkan uraian diatas Puskesmas Kolakaasi Kabupaten Kolaka merupakan jumlah terendah cakupan pemberian tablet Fe pada ibu hamil maka dari itu peneilit tertarik untuk melakukan penelitian pada Puskesmas tersebut.

\section{METODE}

Penelitian ini merupakan jenis penelitian kuantitatif dengan desain penelitian observasional analitik menggunakan pendekatan studi kasus kontrol (Case control study) untuk menganalisis faktor risiko pengetahuan dan efek samping terhadap kepatuhan konsumsi tablet Fe pada ibu hamil di wilayah kerja Puskesmas Kolakaasi Kabupaten Kolaka tahun 2019. Populasi dalam penelitian ini yaitu jumlah seluruh ibu hamil yang berada di wilayah kerja Puskesmas Kolakaasi yakni 197 ibu hamil. Sampel dalam penelitian ini berjumlah 70 yang terdiri dari 35 kasus dan 35 kontrol, pengambilan sampel menggunakan teknik simple random sampling. 
HASIL

a. Karakteristik Responden

Tabel 1. Distribusi Responden Menurut Umur pada Ibu Hamil di Wilayah Kerja Puskesmas Kolakaasi Kabupaten Kolaka

\begin{tabular}{cccccccc}
\hline No. & Umur Ibu & \multicolumn{2}{c}{ Kasus } & \multicolumn{2}{c}{ Kontrol } & \multicolumn{2}{c}{ Total } \\
\cline { 3 - 8 } & Hamil & $\mathbf{n}$ & \% & $\mathbf{N}$ & $\%$ & $\mathbf{n}$ & $\%$ \\
\hline 1. & 15 tahun & 3 & 8,6 & 0 & 0 & 3 & 4,3 \\
\hline 2. & 16 tahun & 3 & 8,6 & 3 & 8,6 & 6 & 8,6 \\
\hline 3. & 17 tahun & 3 & 8,6 & 1 & 2,9 & 4 & 5,7 \\
\hline 4. & 18 tahun & 2 & 5,7 & 2 & 5,7 & 4 & 5,7 \\
\hline 5. & 19 tahun & 3 & 8,6 & 2 & 5,7 & 5 & 7,1 \\
\hline 6. & 20 tahun & 2 & 5,7 & 4 & 11, & 6 & 8,6 \\
& & & & & 4 & & \\
\hline 7. & 21 tahun & 4 & 11, & 6 & 17, & 10 & 14, \\
& & & 4 & & 1 & & 3 \\
\hline 8. & 22 tahun & 4 & 11, & 5 & 14, & 9 & 12, \\
& & & 4 & & 3 & & 9 \\
\hline 9. & 23 tahun & 3 & 8,6 & 4 & 11, & 7 & 10. \\
& & & & & 4 & & 0 \\
\hline 10 & 24 tahun & 8 & 22, & 8 & 22, & 16 & 22, \\
& & & 9 & & 9 & & 9 \\
\hline & Total & $\mathbf{3 5}$ & $\mathbf{1 0 0}$ & $\mathbf{3 5}$ & $\mathbf{1 0 0}$ & $\mathbf{7 0}$ & $\mathbf{1 0 0}$ \\
\hline
\end{tabular}

Sumber : Data Primer, Maret 2020

Tabel 2. Distribusi Responden Menurut Umur Kehamilan pada Ibu Hamil di Wilayah Kerja Puskesmas Kolakaasi Kabupaten Kolaka

\begin{tabular}{llcccccc}
\hline No. & $\begin{array}{c}\text { Umur } \\
\end{array}$ & Kehamilan & \multicolumn{2}{c}{ Kasus } & \multicolumn{2}{c}{ Kontrol } & \multicolumn{2}{c}{ Total } \\
\cline { 3 - 8 } & & $\mathbf{n}$ & $\mathbf{\%}$ & $\mathbf{N}$ & $\mathbf{\%}$ & $\mathbf{N}$ & $\mathbf{\%}$ \\
\hline 1. & 7 bulan & 12 & 34,3 & 3 & 8,6 & 15 & 21,4 \\
2. & 8 bulan & 11 & 31,4 & 8 & 22,9 & 19 & 27,1 \\
\hline 3. & 9 bulan & 9 & 25,7 & 12 & 34,3 & 21 & 30,0 \\
\hline 4. & Pasca & 3 & 8,6 & 12 & 34,3 & 15 & 21,4 \\
& melahirkan & & & & & & \\
\hline & Total & $\mathbf{3 5}$ & $\mathbf{1 0 0}$ & $\mathbf{3 5}$ & $\mathbf{1 0 0}$ & $\mathbf{7 0}$ & $\mathbf{1 0 0}$
\end{tabular}

Sumber: Data Primer, Maret 2020

Tabel 3. Distribusi Masing-Masing Variabel dengan Kepatuhan Konsumsi Tablet Fe pada Ibu Hamil di Wilayah Kerja Puskesmas Kolakaasi Kabupaten Kolaka

\begin{tabular}{|c|c|c|}
\hline Variabel & $\begin{array}{c}\text { Jumlah } \\
\text { (n) }\end{array}$ & $\begin{array}{c}\text { Presentase } \\
(\%)\end{array}$ \\
\hline \multicolumn{3}{|l|}{ 1. Pengetahuan } \\
\hline Kurang & 26 & 37,1 \\
\hline Cukup & 44 & 62,9 \\
\hline Total & 70 & 100 \\
\hline \multicolumn{3}{|l|}{ 2. Efek Samping } \\
\hline Ada Keluhan & 46 & 65,7 \\
\hline Tidak Ada Keluhan & 24 & 34,3 \\
\hline Total & 70 & 100 \\
\hline
\end{tabular}

Sumber : Data Primer, Maret 2020 b. Analisis Bivariat

Tabel 4. Analisis Faktor Risiko Pengetahuan dengan Kepatuhan Konsumsi Tablet Fe pada Ibu Hamil di Wilayah Kerja Puskesmas Kolakaasi Kabupaten Kolaka

\begin{tabular}{|c|c|c|c|c|c|c|c|c|c|}
\hline \multirow{3}{*}{ No } & \multirow{3}{*}{$\begin{array}{c}\text { Pengeta } \\
\text { huan }\end{array}$} & \multicolumn{4}{|c|}{ Konsumsi Tablet Fe } & & & \multirow[b]{2}{*}{ OR } & \multirow{2}{*}{$\begin{array}{l}\mathrm{Cl} \\
\text { (95 } \\
\%)\end{array}$} \\
\hline & & \multicolumn{2}{|c|}{ Kasus } & \multicolumn{2}{|c|}{ Kontrol } & \multicolumn{2}{|c|}{ Total } & & \\
\hline & & $\mathbf{N}$ & $\%$ & $n$ & 0 & $N$ & $\%$ & & \\
\hline 1. & $\mathrm{Ku}$ & 14 & 40,0 & 12 & 34,3 & 26 & $\begin{array}{l}37 \\
1\end{array}$ & 1,27 & 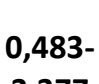 \\
\hline 2. & Cukup & 21 & 60,0 & 23 & 65,7 & 44 & 62,7 & & \\
\hline & Total & 35 & 100 & 35 & 100 & 70 & 100 & & \\
\hline
\end{tabular}

Sumber: Data Primer, Maret 2020

Tabel 5. Analisis Faktor Risiko Efek Samping dengan Kepatuhan Konsumsi Tablet Fe pada Ibu Hamil di Wilayah Kerja Puskesmas Kolakaasi Kabupaten Kolaka

\begin{tabular}{|c|c|c|c|c|c|c|c|c|c|}
\hline \multirow{3}{*}{ No } & \multirow{3}{*}{$\begin{array}{c}\text { Efek } \\
\text { Sampin } \\
\mathbf{g}\end{array}$} & \multicolumn{4}{|c|}{ Konsumsi Tablet Fe } & & & \multirow[b]{2}{*}{ OR } & \multirow{3}{*}{$\begin{array}{l}\mathrm{Cl} \\
(95 \\
\%) \\
\end{array}$} \\
\hline & & \multicolumn{2}{|c|}{ Kasus } & \multicolumn{2}{|c|}{ Kontrol } & \multicolumn{2}{|c|}{ Total } & & \\
\hline & & $\mathbf{N}$ & $\%$ & $\mathbf{n}$ & $\%$ & $\mathbf{N}$ & $\%$ & & \\
\hline 1. & $\begin{array}{l}\text { Ada } \\
\text { Keluhan }\end{array}$ & 29 & 82,9 & 17 & 48,6 & 46 & $\begin{array}{l}65, \\
7 \\
\end{array}$ & 11 & \\
\hline 2. & $\begin{array}{l}\text { Tidak } \\
\text { Ada } \\
\text { Keluhan }\end{array}$ & 6 & 17,1 & 18 & 51,4 & 24 & 34,3 & 8 & $\begin{array}{l}1,102- \\
15,389\end{array}$ \\
\hline & Total & 35 & 100 & 35 & 100 & 70 & 100 & & \\
\hline
\end{tabular}

Sumber: Data Primer, Maret 2020

\section{DISKUSI}

Faktor Risiko Pengetahuan dengan Kepatuhan Konsumsi Tablet Fe Pada Ibu Hamil di Wilayah Kerja Puskesmas Kolakaasi Kabupaten Kolaka

Pengetahuan merupakan domain yang sangat penting untuk terbentuknya tindakan seseorang. Pengetahuan merupakan akumulasi dari pengalaman dan pendidikan yang didapat oleh orang sebelumnya, makin tinggi tingkat pendidikan seseorang makin tinggi pula pengetahuannya tentang sesuatu. Pengetahuan merupakan predisposisi terjadinya perilaku dan pengetahuan merupakan domain terbentuknya perilaku ${ }^{7}$.

Hasil penelitian menunjukkan bahwa pengetahuan bukan merupakan faktor risiko kepatuhan konsumsi tablet Fe pada ibu hamil di wilayah kerja Puskesmas Kolakaasi Kabupaten Kolaka. Hal ini dibuktikan dengan hasil analisis bivariat faktor risiko pengetahuan dengan kepatuhan konsumsi tablet Fe pada ibu hamil di wilayah kerja Puskesmas Kolakaasi Kabupaten Kolaka nilai OR=1,278 (95\% Cl;0,483-3,377). Secara statistik menunjukkan tidak ada hubungan yang bermakna 
antara faktor risiko pengetahuan dengan kepatuhan konsumsi tablet Fe pada ibu hamil di wilayah Kerja Puskesmas Kolakaasi Kabupaten Kolaka.

Tingkat pengetahuan seseorang mengenai tablet besi (Fe) berpengaruh terhadap perilaku dalam memilih makanan yang mengandung zat besi. Hal ini menunjukkan bahwa pengetahuan sangat penting peranannya dalam menentukan kepatuhan dalam mengkonsumsi tablet besi (Fe) dengan adanya pengetahuan tentang zat besi, ibu hamil akan tahu bagaimana menyimpan dan menggunakan tablet besi. Memperbaiki konsumsi tablet besi merupakan salah satu bantuan terpenting yang dapat dilakukan untuk meningkatkan kualitas status gizi pada ibu hamil.

Penelitian ini sejalan dengan penelitian Purnamasari et.al (2016), menunjukkan bahwa pengetahuan responden tentang tablet Fe sebagian besar tinggi yaitu 64,2\%. Sedagkan responden dengan tingkat pengetahuan rendah sebesar 35,8\%. Secara statistik tidak ada hubungan bermakna pengetahuan dengan kepatuhan ibu hamil dalam mengkonsumsi tablet Fe dapat dilihat dari nilai $p$ $0,284(>0,05)$. Hal ini mungkin terjadi karena selain pengetahuan masih ada variabel lain yang lebih berhubungan dengan kepatuhan ibu hamil dalam mengkonsumsi tablet $\mathrm{Fe}^{8}$.

Namun tidak sejalan dengan penelitian yang dilakukan oleh Sadore A et.al., (2015) yang menyatakan bahwa ada hubungan secara bermakna pengetahuan tentang suplemen zat besi dengan kepatutuhan konsumsi suplemen zat besi pada ibu hamil. Dari hasil analisis diperoleh nilai $A O R=4,451$, $(95 \% \mathrm{Cl}=2,027-9,777)^{9}$.

Berdasarkan hasil penelitian ini pada umunya pengetahuan ibu hamil di wilayah kerja Puskesmas Kolakaasi sudah baik, hal ini juga dipengaruhi oleh peran petugas kesehatan yang sudah baik dalam melakukan tindakan agar ibu hamil memahami akan pentingnya tablet $\mathrm{Fe}$, juga petugas kesehatan selalu memberikan atau menyampaikan penyuluhan disaat ibu mengambil tablet $\mathrm{Fe}$ di Puskesmas, disaat kegiatan posyandu ataupun pada saat kelas ibu hamil.

Faktor Risiko Efek Samping dengan Kepatuhan Konsumsi Tablet Fe Pada Ibu Hamil di Wilayah Kerja Puskesmas Kolakaasi Kabupaten Kolaka

Pada beberapa orang minum tablet Fe dapat menimbulkan gejala-gejala seperti mual, nyeri didaerah lambung, muntah, kadang-kadang terjadi diare dan sulit buang air besar. Selain itu tablet Fe yang dikonsumsi setiap hari menimbulkan rasa bosan sehingga seringkali ibu hamil lupa dan merasa malas untuk mengkonsumsinya ${ }^{10}$.
Hasil penelitian menunjukkan bahwa efek samping merupakan faktor risiko kepatuhan konsumsi tablet Fe pada ibu hamil di wilayah kerja Puskesmas Kolakaasi Kabupaten Kolaka. Hal ini dibuktikan dengan hasil analisis bivariat faktor risiko efek samping dengan kepatuhan konsumsi tablet Fe pada ibu hamil di wilayah kerja Puskesmas Kolakaasi Kabupaten Kolaka nilai OR=5,118 (95\% Cl;1,70215,389). Secara statistik menunjukkan hubungan yang bermakna antara faktor risiko efek samping dengan kepatuhan konsumsi tablet Fe pada ibu hamil di wilayah Kerja Puskesmas Kolakaasi Kabupaten Kolaka.

Penelitian ini menunjukkan bahwa ibu hamil yang mengalami keluhan memiliki risiko 5,1 dibandingkan dengan responden pada kelompok yang tidak mengalami keluhan.

Frekuensi efek samping ini berkaitan langsung dengan dosis zat besi. Mual pada masa kehamilan adalah proses fisologi sebagai dampak dari terjadinya adaptasi hormonal. Selain itu mual dapat terjadi pada ibu hamil sebagai efek samping dari minum tablet Fe. Ibu hamil yang mengalami mual sebagai dampak kehamilannya dapat merasakan mual yang lebih parah dibandingkan dengan ibu hamil yang tidak mengalami keluhan mual sebelumnya. Ada beberapa cara mengatasi mual akibat minum tablet Fe. Salah satu cara yang dianjurkan untuk mengurangi mual sebagai efek samping dari mengkonsumsi tablet Fe adalah dengan mengurangi dosis tablet Fe dari $1 \times 1$ tablet sehari menjadi $2 \times 1 / 2$ tablet sehari ${ }^{11}$.

Hasil penelitian ini sejalan dengan penelitian yang dilakukan oleh Saptarini Ika (2015) menyatakan bahwa efek samping konsumsi tablet Fe telah lama diyakini menjadi salah satu faktor penyebab buruknya konsumsi tablet Fe pada ibu hamil. Pada penelitian ini keluhan minum tablet Fe memberikan pengaruh bermakna terhadap jumlah tablet Fe yang diminum selama kehamilan $p=0,002$. Terdapat 49 responden menyatakan mengalami keluhan saat minum tablet Fe. Keluhan terbanyak yang dialami responden adalah mual (73,6\%). Selain mual, responden juga mengeluhkan tablet besi yang mereka minum berbau tidak enak (18,9\%) dan mengeluhkan pusing setelah minum tablet $\mathrm{Fe}(7,5 \%)$. Pada beberapa orang juga menimbulkan efek samping seperti nyeri didaerah lambung, kadang terjadi diare atau sulit buang air besar ${ }^{12}$.

Hal tersebut serupa dengan hasil penelitian yang dilakukan oleh Rahmawati (2012) yang menyatakan bahwa efek samping adalah efek yang tidak menyenangkan yang dirasakan ibu hamil setelah mengkonsumsi tablet Fe. Penelitian yang dilakukan di puskesmas Halmahera menunjukkan bahwa sebagian besar responden $(62,5 \%)$ merasakan 
Jurnal Ilmiah Mahasiswa Kesehatan Masyarakat Vol. 5/No. 2/ April 2020; Issn: 2502-731X

adanya efek samping setelah mengkonsumsi tablet Fe. Akan tetapi hal ini tidak sesuai dengan penelitian sebelumnya yang menyatakan tidak ada hubungan antara efek samping gastroinstestinal seperti mual, muntah, nyere ulu hati, dan diare dengan empat dosis yang di uji cobakan yaitu : $20 \mathrm{mg}, 40 \mathrm{mg}, 60$ $\mathrm{mg}$, dan $80 \mathrm{mg}$. konsumsi tablet Fe pada malam hari juga dilakukan dalam upaya mencegah mual setelah minum tablet $\mathrm{Fe}^{\cdot 13}$.

Berdasarkan hasil wawancara sesuai dengan hasil penelitian terdahulu beberapa alasan yang mempengaruhi ibu hamil tidak minum tablet Fe yang diterima dari Puskesmas Kolakaasi, sebagian besar mengatakan merasa mual dan muntah setelah minum tablet $\mathrm{Fe}$, baunya tidak enak, ada pula yang mengatakan dirinya sehat dan tidak sedikit juga mengatakan susah buang air besar setelah minum tablet Fe. Oleh karena itu, sebaiknya ibu minum tablet Fe sebaiknya dilakukan pada jeda makan atau saat lambung tidak banyak makanan, karena pada keadaan ini zat besi akan mudah diserap sehingga ibu hamill dia anjurkan minum tablet Fe menjelang tidur disertai dengan minuman atau makanan yang sumber Vitamin C. Berdasarkan hasil rekapan jawaban dari ibu hamil selain efek samping yang dikeluhkan sebagian besar juga tidak patuh dari segi cara minum tablet $\mathrm{Fe}$, seperti ibu hamil minum susu, kopi dan teh bersamaan dengan minum tablet Fe tidak sedikit juga ibu hamil minum tablet $\mathrm{Fe}$ menggunakan air putih.

\section{SIMPULAN}

1. Pengetahuan bukan merupakan faktor risiko kepatuhan konsumsi tablet Fe pada ibu hamil di wilayah kerja Puskesmas Kolakaasi Kabupaten Kolaka

2. Efek samping merupakan faktor risiko kepatuhan konsumsi tablet Fe pada ibu hamil di wilayah kerja Puskesmas Kolakaasi Kabupaten Kolaka

\section{SARAN}

1. Diharapkan bagi ibu hamil agar mencukupi konsumsi tablet Fe sebanyak 90 tablet selama kehamilan dan lebih memperhatikan kesehatan dirinya dengan menjaga kebutuhan nutrisi selama kehamilan.

2. Diharapkan tenaga kesehatan mengontrol secara berkala kepatuhan ibu hamil minum tablet Fe, karena obat tablet Fe menimbulkan efek samping. Selain itu, tenaga kesehatan juga harus gencar memberikan konseling atau penyuluhan mengenai efek samping dari tablet Fe bahwa efek samping yang dirasakan tidak membahayakan ibu dan bayinya.

3. Hasil penelitian ini diharapkan dapat menjadi salah satu acuan bagi penelitian berikutnya yang melakukan penelitian sejenis dengan variabel yang berbeda mengenai kepatuhan dalam mengkonsumsi tablet Fe.

\section{DAFTAR PUSTAKA}

1. World Health Organization. 2012. Guideline Daily Iron and Folic Acid Supplementation in Pregnant Woman. WHO Library Cataloguing in Publication Data

2. World Health Organization. Micronutrient Deficiencies..

Http://Www.Who.Int/Nutrition/Topics/Ida/En/In dex.Html

3. Kementerian Kesehatan RI, 2013. Cakupan Pembeian Tablet Fe Pada Ibu Hamil

4. Kementerian Kesehatan RI Badan Penelitian Dan Pengembangan. (2018). Hasil Utama Riset Kesehatan Dasar. Kementrian Kesehatan Republik Indonesia, 1-100. Https://Doi.Org/1 Desember 2013

5. Dinas Kesehatan Provinsi Sulawesi Tenggara, 2018. Cakupan pemberian tablet Fe Pada Ibu Hamil.

6. Dinas Kesehatan Kabupaten Kolaka, 2018. Profil Kesehatan Kabupaten Kolaka

7. Purnamasari, G., Margawati, A., \& Widjanarko, B. (2016). Pengaruh Faktor Pengetahuan Dan Sikap Terhadap Kepatuhan Ibu Hamil Dalam Mengkonsumsi Tablet Fe Di Puskesmas Bogor Tengah. Jurnal Promosi Kesehatan Indonesia, 11(2), 100. Https://Doi.Org/10.14710/Jpki.11.2.100-115

8. sSadore A. Abebe, \& Aman (2015). Compliance With Iron-Folate Supplement And Associated Factors Among Antenatal Care Anttedant Mothers Ini Misha District, South Ethiopia: Community Based Cross Sectional.

9. Achadi, Endang Laksminingsih. (2013). Faktorfaktor Yang Berhubungan Dengan Kepatuhan Ibu Mengkonsumsi Tablet Besi-Folat Selama Kehamilan. Jurnal Gizi dan Pangan, 8 (1), 63-70.

10. Susiloningtyas, I. (2012). Pemberian Zat Besi (Fe) Dalam Kehamilan Oleh: Is Susiloningtyas. Majalah Ilmiah Sultan Agung, 50, 128.

11. Saptarini, I., Susilowati, A., Teknologi, P., \& Masyarakat, K. (2015). Faktor Faktor Yang Berhubungan Dengan Konsumsi Tablet Besi Pada Ibu Hamil Di Kelurahan Kebon Kelapa, Bogor Factors Affecting Iron Tablets Consumption In Pregnant Women In Kebon Kelapa, Bogor. 9-17.

12. Saptarini, I., Susilowati, A., Teknologi, P., \& Masyarakat, K. (2015). Faktor Faktor Yang Berhubungan Dengan Konsumsi Tablet Besi Pada Ibu Hamil Di Kelurahan Kebon Kelapa, Bogor Factors Affecting Iron Tablets Consumption In Pregnant Women In Kebon Kelapa, Bogor. 9-17. 
Jurnal Ilmiah Mahasiswa Kesehatan Masyarakat Vol. 5/No. 2/ April 2020; Issn: 2502-731X

13. Rahmawati Febriana, Hertanto Wahyu Subagio. (2012). Kepatuhan Konsumsi Tablet Besi Folat Pada Ibu Hamil dan Faktor Yang Mempengaruhi. of Nutrition College, 1(1), 55-62. 